\title{
Remote Sensing Mapping of Land Use and Land Cover Changes in Upper Casamance, Senegal, 1987-2018
}

\author{
Email address: \\ b.solly1087@zig.univ.sn (B. Solly) \\ ${ }^{*}$ Corresponding author
}

Boubacar Solly ${ }^{*}$, El Hadji Balla Dieye, Oumar Sy

Department of Geography, Assane SECK University of Ziguinchor, Ziguinchor, Senegal

\section{To cite this article:}

Boubacar Solly, El Hadji Balla Dieye, Oumar Sy. Remote Sensing Mapping of Land Use and Land Cover Changes in Upper Casamance, Senegal, 1987-2018. American Journal of Remote Sensing. Vol. 8, No. 2, 2020, pp. 35-49. doi: 10.11648/j.ajrs.20200802.11

Received: September 6, 2020; Accepted: September 19, 2020; Published: September 28, 2020

\begin{abstract}
In order to study the evolution of land use and the changes in land cover in Upper Casamance, from Landsat images acquired in 1987 and 2018, we used a method of multistage unsupervised classification. Recently developed to mapping and quantification of vegetation land cover changes in West-African coastal, this method is based on the following stages: first classification (K-means) over 15 classes, interpretation of the spectral signatures of the resulting classes followed by reclassification according to the chosen nomenclature, creation of thematic masks, classifications on masks, and finally reclassification. With the only difference, our study aims also to contribute, methodologically, to the knowledge of the spectral profiles of plant formation types. On a thematic level, the results show that between 1987 and 2018, forest areas decreased by $377,118.7$ ha (or 27.4\%), while wooded areas and agricultural and soil surfaces increased by $263,172.4$ ha (or 19.1\%) and 1560 75.5 ha $(11.3 \%)$. In terms of change, deforestation by increasing agricultural and soil surfaces is noted along the border with the Gambia, savanization and anthropization is noted along the central part, and stability of forest surfaces followed by a slight increase in savannas and agricultural and soil surfaces is noted in the south.
\end{abstract}

Keywords: Soil Occupation, Change Maps, Unsupervised Classification, Vegetation Cover, Upper Casamance

\section{Introduction}

Monitoring of land use and land cover changes is of major interest to States for better management of resources and the environment. In West Africa, particularly Senegal, this follow-up takes place in a general context marked by variability in climate conditions [1] and through deforestation and land degradation [2-7] for more than five decades. It takes on a particularly interesting dimension through the identification, description and analysis of the current process.

Indeed, FAO studies [8] found that between 1990 and 2015, Africa lost 125,238,000 ha of its forest area when Asia, Europe and North and Central America experienced a significant increase. In Sudano-Sahelian West Africa, [9] showed, based on literature studies of \pm 10 years between 1955 and 1995 , a loss of $2 \%$ of forest area per year during this period. In Senegal, the loss is estimated at 1,075,000 ha, or 11.49 per cent between 1990 and 2015 [8]. Directly impacted by agricultural development, [7] reports that woodlands and galleries, as well as Sudanian and Sahelian savannas, decreased by 11,930 km² between 1975 and 2013 . In southern Senegal, particularly in the Vélingara department, the loss of vegetation cover is 74,182 ha in 31 years [10].

Indeed, with population growth and the strong expansion in food demand, vast areas of forest and wooded land are converted into agricultural land or pasture land. In addition to these needs, wood for energy and service is naturally a major contributor to the degradation of forest ecosystems [11]. It is also not forgetting the wildfires [12] and the degradation of the climatic conditions noted since the 1970s [3, 4, 13, 14], which amplified changes in land use and cover. The latter are considered to be the main factor in changing vegetation cover in West Africa [15]. It determines the zoning of the plant cover and the amount of plant biomass.

Through the tree and its various components, the plant cover regulates the climate, captures carbon, protects the soil, supplies energy wood, firewood and service, serves as a pharmacy, etc. [16-18]. At the Rio 92 conference, it was recognized that they are a natural capital and heritage to be passed on to future generations [19]. Thereby, any 
substitutability of this capital leads to adverse environmental and socio-economic impacts $[6,20,21]$. Therefore, their rational management is in the interests of the countries to which they belong, while having a great price for the environment. However, a resource cannot be managed sustainably without the necessary information on its availability.

For this purpose, remote sensing is positioned as an effective and methodical means of evaluation and monitoring in time and space. With the availability of satellite images, it has become a preferred tool for evaluating plant resources [2, 5-7, 22-26]. Through classification methods (supervised or unsupervised), it matches elements of an image scene materialized by pixels, represented by radiometric values, to a set of thematic classes known a priori or not [27]. Also known as assisted or directed classification [28], supervised classification is a method that requires a sufficient number of control areas for class definition. This is not the case for unsupervised classification. It has the advantage of grouping the pixels of an image into spectral classes according to their signatures and assigning them a thematic meaning [29, 30]. According to [31], the main difference between these two classifications is mainly the availability and use of the reference data. Thus, it is sometimes impossible to use the supervised classification because of the lack of the availability of truths on the ground relating to the ancient years. Because, the reference data must be from the same year as the images to be classified to avoid errors related to changes in occupancy between years. This is not always the case. In addition, in space remote sensing, vegetation mapping is based on the ability to recognize plant formations based on their radiometric characteristics according to classification criteria [32]. Therefore, the choice of classification method is very important. To address these situations, this study adopted a method of multistage unsupervised classification. It was developed by [33] to study landscape dynamics of "Rivières-du-Sud" from Salum Delta (Senegal) to Rio Geba (Guinea-Bissau). Recently, it was used by [25] to study the dynamics of forest landscapes in Southern Senegal. However, these studies did not go into detail in terms of differentiating plant formations. Spectral profiles of land-use classes do not concern plant formation types. In view of this, our study proposes to analyze changes in vegetation cover in Upper-Casamance by adopting the same method, but at the same time contributing to knowledge of the spectral profiles of the different plant formations.

\section{Study Area}

Upper Casamance (or region of Kolda) is located in the south of Senegal between $12^{\circ} 20$ and $13^{\circ} 40$ latitude North, and between $13^{\circ} \mathrm{C}$ and $16^{\circ} \mathrm{W}$ longitude. It is limited to the East by the Tambacounda region (Eastern Senegal), to the West by the Sedhiou region (Middle Casamance), to the North by the Republic of the Gambia and to the South by the Republics of Guinea and Guinea-Bissau (Figure 1). It covers an area of $13,721 \mathrm{~km}$ or $7 \%$ of the national territory. It has 14 classified forests with a total area of 284333 ha.

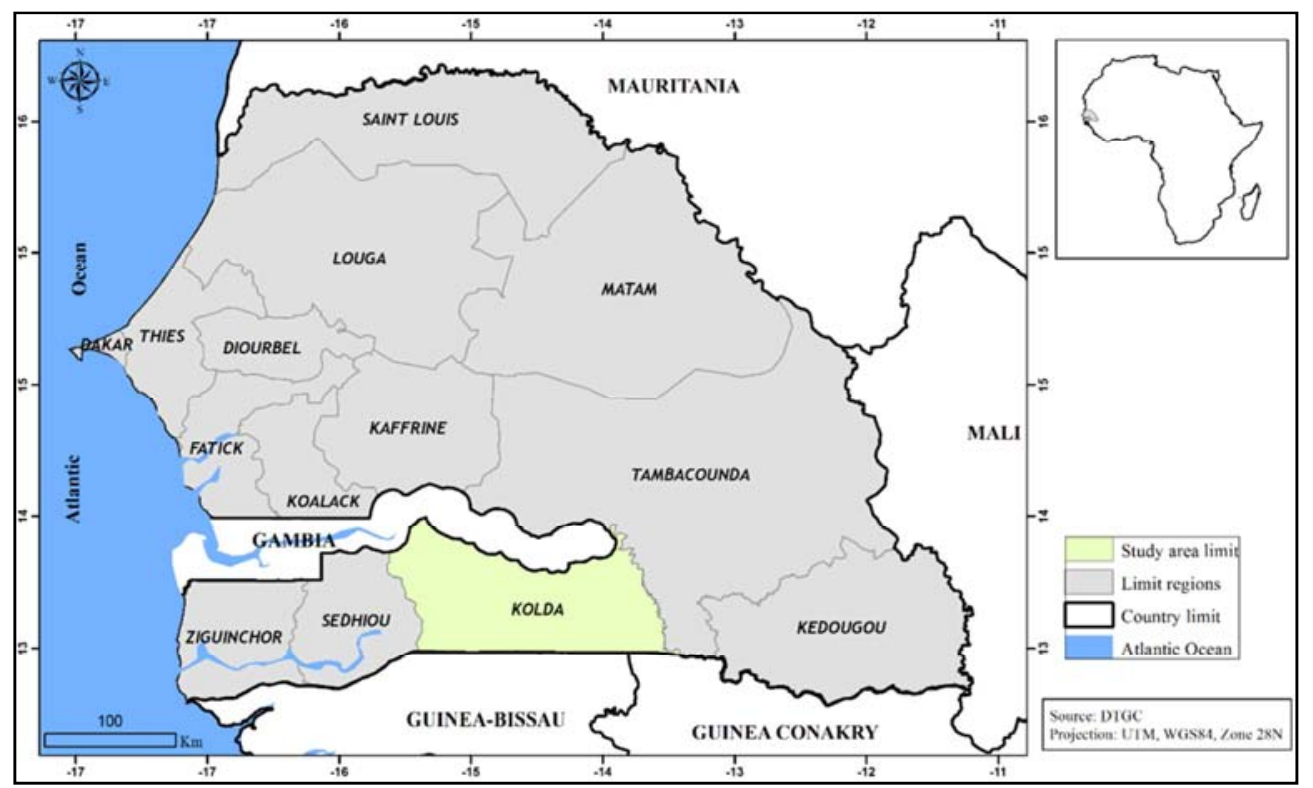

Figure 1. Location of study area in southern Senegal.

The climate falls within the continental South Sudanese domain with annual precipitation between 1000 and $1500 \mathrm{~mm}$ [34]. To the north, a small, less watered portion belongs to the north-suddenly continental domain (annual precipitation between 500 and $1000 \mathrm{~mm}$ ). Like the Sahel countries, the study area is marked by the long dry period of the $70 \mathrm{~s}$ and $80 \mathrm{~s}$. A discontinuity to wet conditions has been noted since 1999, although annual precipitation remains lower than pre-1970 [1].

In terms of vegetation, the climate results in formations with a Guinean affinity, such as the woodland, the gallery forest, the wooded savanna and the wooded to shrub savanna (Figure 2a-d). The transformation of the forest into a savanna 
(savanization) takes place through a mosaic "savanna-forest" in which the forest gradually gives way to savanna.
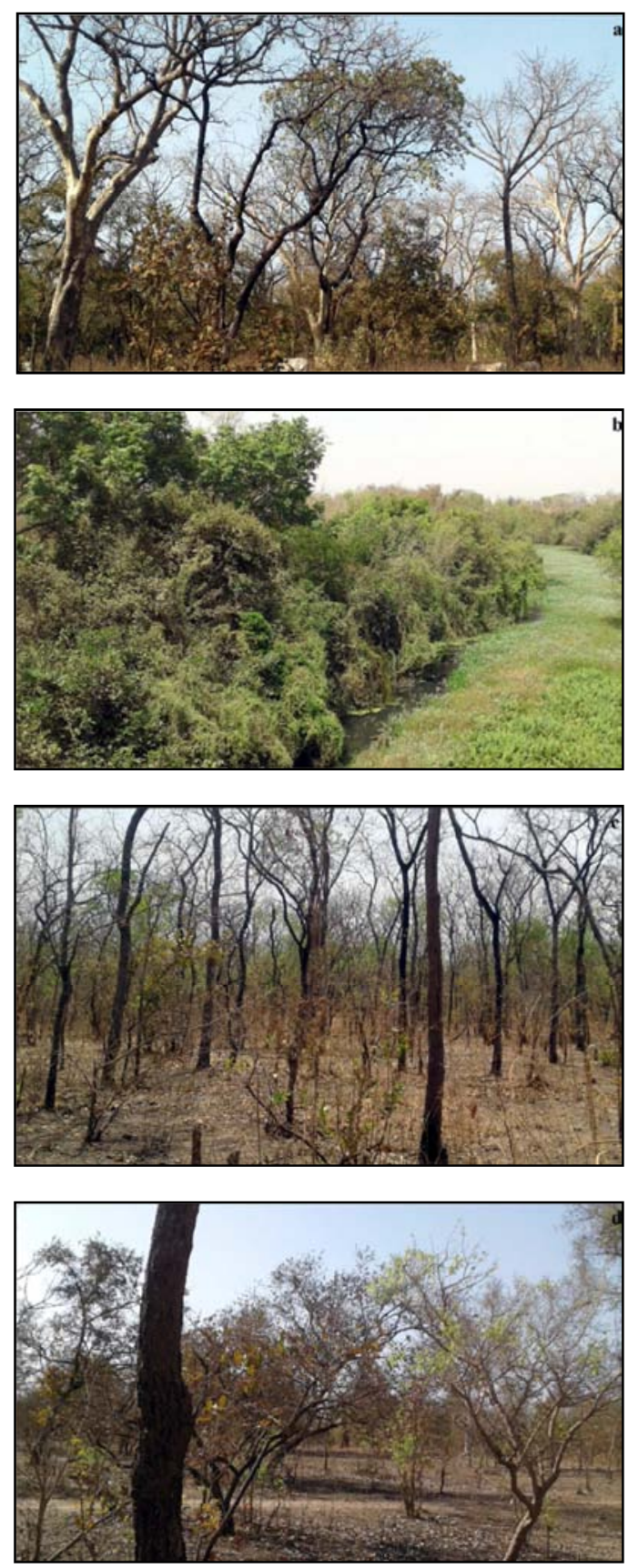

Figure 2. Types of plant formations in the study area (Snapshot: B. Solly, field mission 2018).

As defined during the Yangambi Conference [35, 36], the woodland is an " open stand with small and medium-sized trees whose crowns are more or less contiguous, the entire canopy allowing ample light to filter through; on the ground, grasses are scarce and can be mixed with other suffrutescent or herbaceous plants." The gallery forest is a closed formation of dense forest that accompanies the rivers in the open formations and savanna regions thanks to the humidity they maintain. The wooded savanna is a formation of "trees and shrubs forming a clear canopy that allows light to pass largely"
[37]. The wooded to shrub savanna is a stand of scattered trees and shrubs [36]. It is for the tree savanna, a plant formation with trees and shrubs scattered in the grass rug, and for the shrub savanna, a plant formation characterized by the presence of a continuous herbaceous stratum [35].

\section{Materials and Methods}

\subsection{Materials Used}

To analyze the changes in vegetation cover between 1987 and 2018, we used images from the Landsat satellite (Table 1). This satellite has the advantage of covering our study area with available images, free for download (http://earthexplorer.usgs.gov/), and with a spatial resolution of $30 \mathrm{~m}$ for multispectral bands.

Table 1. Landsat satellite images used.

\begin{tabular}{llllll}
\hline Year & Date & Path & Row & Satellite & Sensor \\
\hline \multirow{2}{*}{1987} & $1987 / 11 / 20$ & 204 & \multirow{2}{*}{051} & Landsat 5 & TM \\
& $1987 / 12 / 15$ & 203 & & & \\
\multirow{2}{*}{2018} & $2018 / 12 / 11$ & 204 & \multirow{2}{*}{051} & Landsat 8 & OLI_TIRS \\
& $2018 / 12 / 04$ & 203 & & & \\
\hline
\end{tabular}

This resolution is sufficient to map and quantify the spatial-temporal evolution of vegetation cover. In addition, the months of shooting (dry season) allow a good spectral contrast between the herbaceous formations and dense woody formations. Two scenes are needed to cover the entire study area. This is scene p204r051 and p203r051.

The data processing was done using the Idrisi TerrSet software (for the processing of satellite images) and Arc Gis 10.5 (for the calculation of surface and the mapping layout). During the field tours, we used a GPS type Garmin eTrex 30x to take geographic coordinates.

\subsection{The Steps of Image Processing}

The processing of the images took place in several stages which are: the geometric correction, the combination of bands followed by the photointerpretation, the classification with its substages, and the confrontation with the reference data.

\subsubsection{Geometric Correction}

The geometric correction of satellite images is a key step before any operation. Because images are taken by different sensors at different times, they have geometric shifts that must be corrected so that they can be superimposed [10, 33]. For this purpose, we used the geo-referencing method of image by image with choice of four bitter dots from the 2018 image used as reference. A second-degree polygon with a selected number of Ground Control Points (GCP) greater than $(n+1)^{2}$ is used to initiate the correction.

\subsubsection{Combination of Bands and Photo-interpretation}

After bringing the images back to the same geometry, we have mosaicked the strips of the two scenes for each of the dates. Thereafter, we combined the PIR, Red, and ACP 1 (after performing the PCA) band with the RGB channels for each 
date to identify, through a visual interpretation, the land-use units to be mapped. Conventional interpretation techniques using the image characteristics such as the color and shape of objects are used. They are supplemented by documentation, land-use maps, and field work. On the basis of these elements, we identified and decided to map eight classes, with different

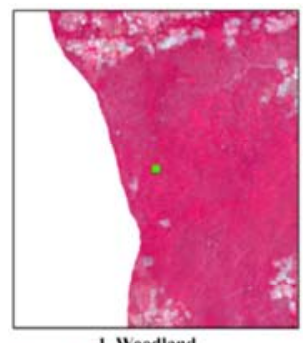

1. Woodland

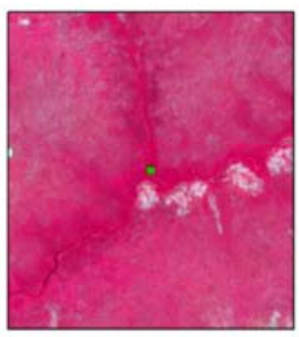

2. Gallery forest
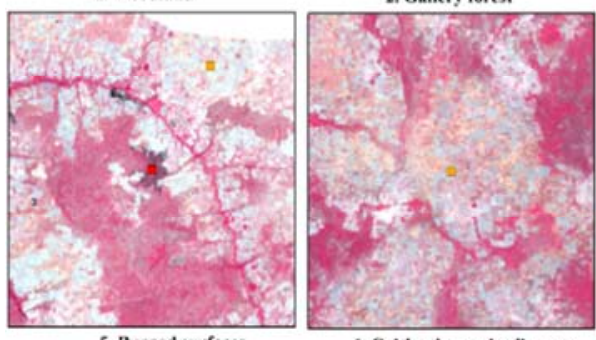

6. Cultivation and soil areas

spectral characteristics, including four types of the plant formations (woodland, gallery forest, wooded savanna, and shrub savanna), the burns (areas affected by fire at the time the images were taken), the agricultural and soil surfaces, the plantations, and the water surfaces (Figure 3). These classes are coded from 1 to 8 .

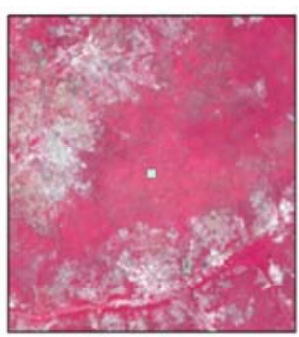

3. Wooded savanna
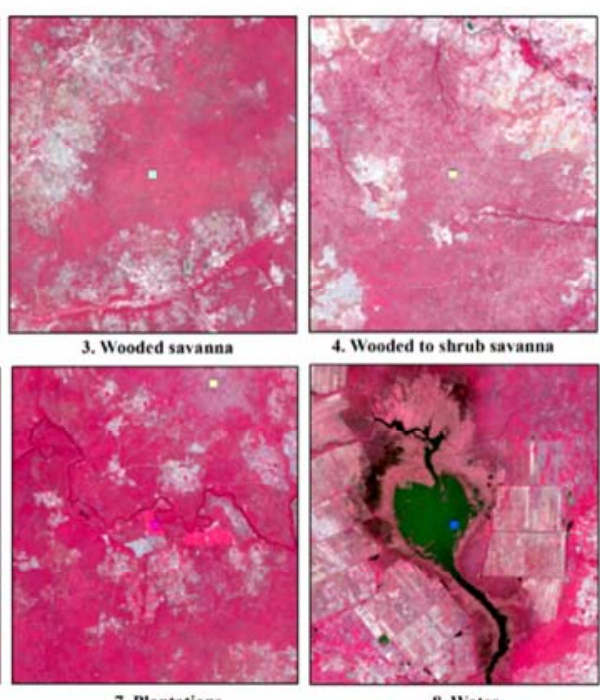

Figure 3. Zoom and color of the land use classes identified from Landsat OLI_TIRS 2018 image.

\subsubsection{Image Classification}

i. Choice of the classification algorithm

Unsupervised method classification algorithms have been widely discussed in recent research [30, 31, 38]. These studies show that there are several algorithms. Among these algorithms, ISODATA [39] and K-means [40] are most commonly used. The results they provide are almost similar [30]. They are often equated with the supervised method in the sense that the number of classes must be given to initialize the process, but not necessarily their parameters
[31]. However, we have favored the K-means algorithm because it has the advantage of assigning pixels, the closest class [41].

ii. First unsupervised classification over fifteen classes and interpretation of radiometric curves

For better class separation, we launched the first classification of fifteen classes using all multispectral bands ranging from blue to infrared $[25,33]$. The result obtained from the 2018 OLI_TIRS image is shown in figures 4 and 5.

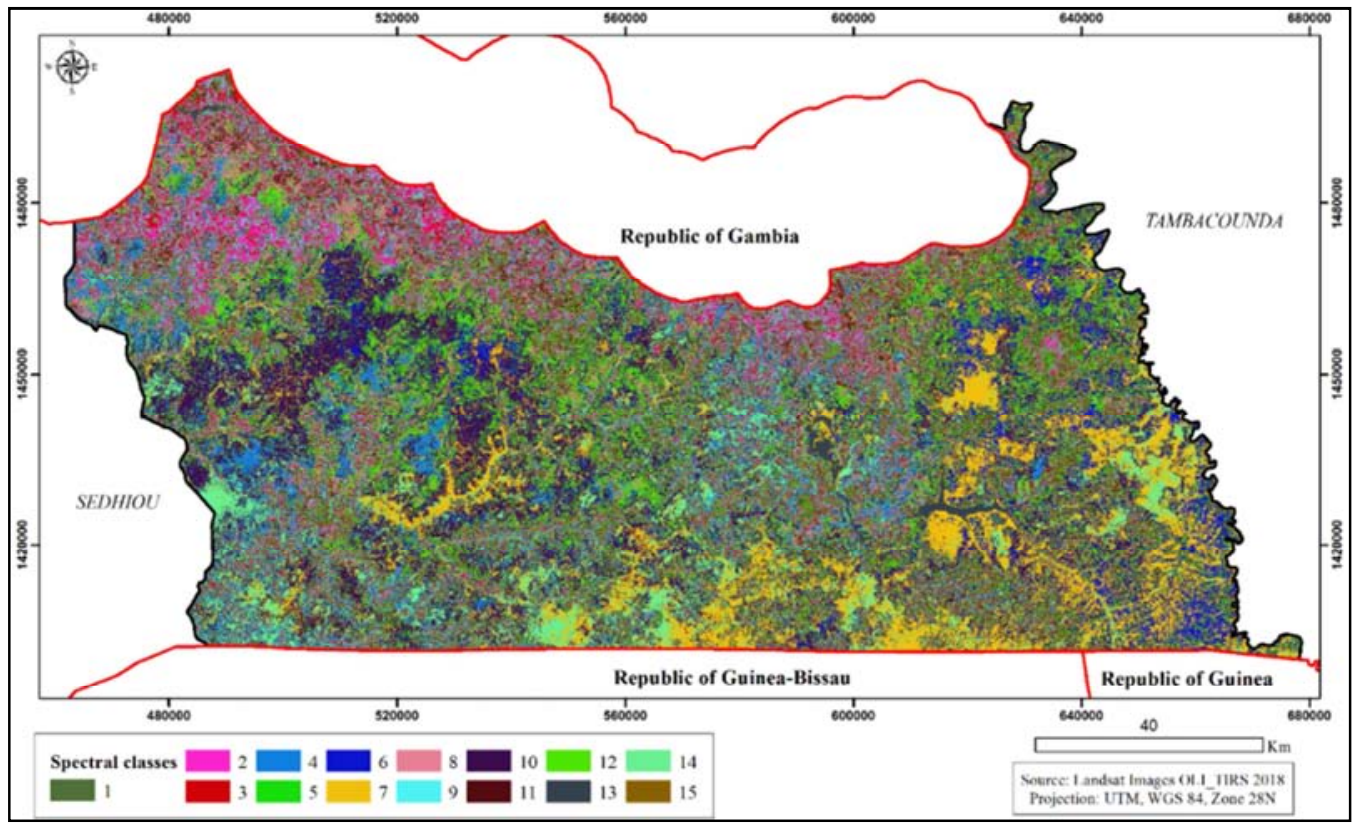

Figure 4. Unsupervised classification into 15 classes of the 2018 Landsat OLI_TIRS image. 


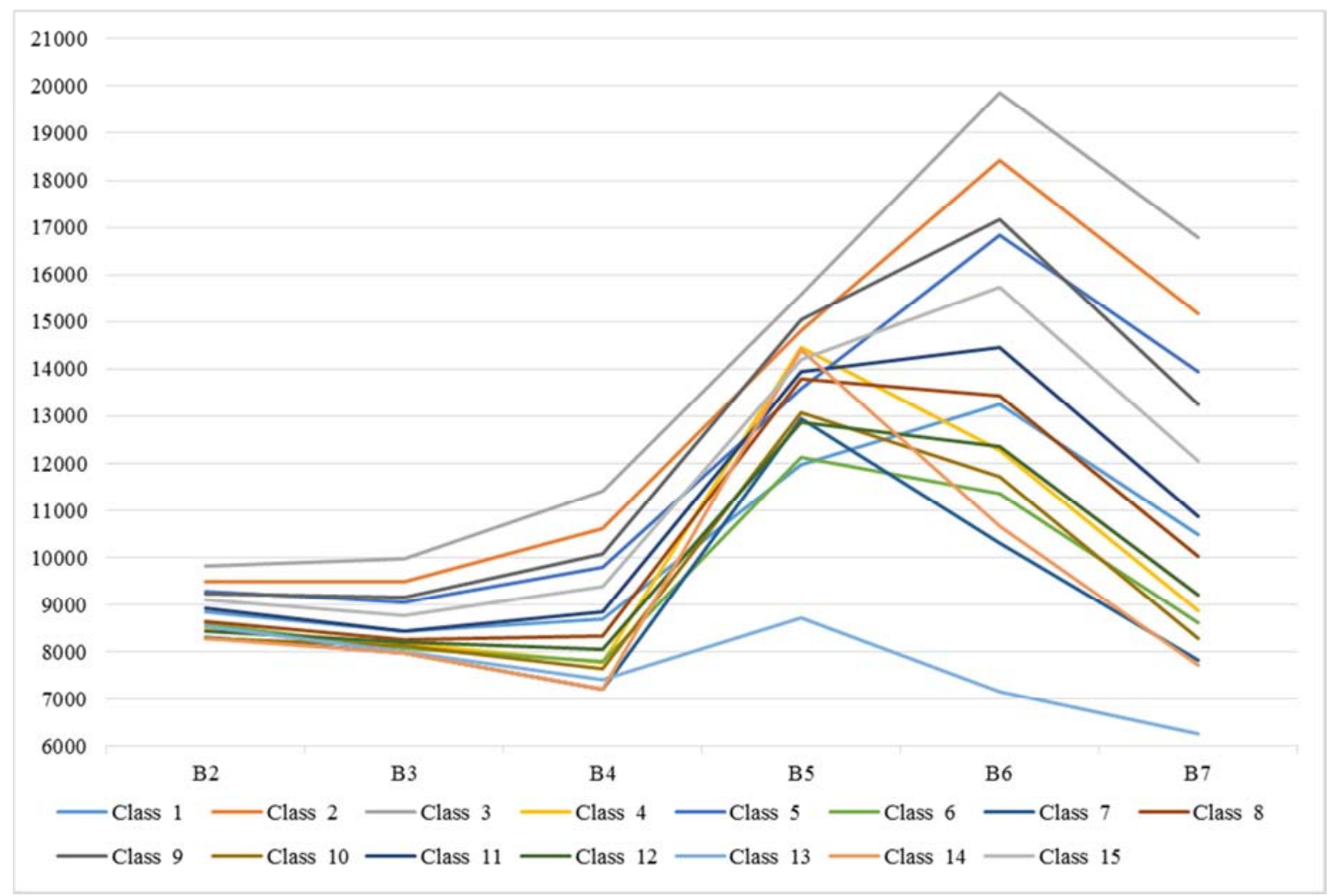

Figure 5. Histograms of the spectral signatures of the unsupervised classification of the 2018 Landsat OLI_TIRS image.

For the interpretation of classes histograms, particularly of plant formations, a detailed literature review was conducted $[25,28,32,33,42-49]$. The results show that natural surfaces are characterized by very large variations in reflectance according to the wavelength. And that, the spectral response of vegetation depends, among other things, on the pigmentation, physiological structure, and water content of the plant [45]. The pigments in the leaves of the plants absorb the light of the visible; whereas a dense structure of plants strongly reflects infrared light. This is why vegetation during chlorophyllian activity reflects strongly in the near infrared [28]. In addition, the denser it is, the stronger its reflectance in the green and near infrared. However, its reflectance remains low in blue and red. When it experiences stress, its chlorophyll content decreases, resulting in an increase in its visible reflectance with values close to those of infrared [50].
In the infrared medium, i.e. above $1.4 \mu \mathrm{m}$, the spectral behavior of plants is dependent on their water content [32]. In fact, a healthy vegetal cover has a significant decrease in reflectance around $1.45 \mu \mathrm{m}$ and $1.9 \mu \mathrm{m}$. The higher the water content of the ground cover, the lower the reflectance [33].

Soils have a strong reflectance of visible to infrared [44]. According to the same source, in the visible, particularly in the red, which corresponds to the 0.63-0.69 $\mu \mathrm{m}$ range, its reflectance values are usually higher than those of the vegetation. In the near infrared, however, they are commonly lower [43]. As for water, it has a strong reflectance in the wavelengths of the visible, particularly in blue, and a nearly zero reflectance in infrared.

On the basis of these interpretive keys, we have noted 6 trends from the 2018 Landsat OLI_TIRS image classification (Figure 6).
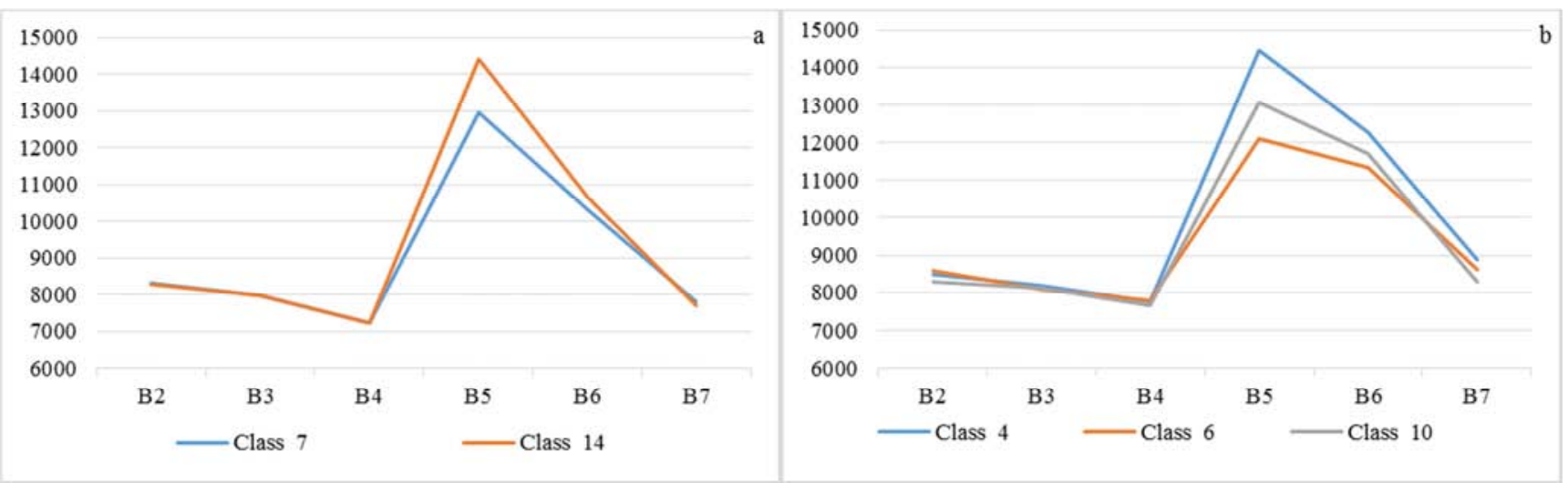


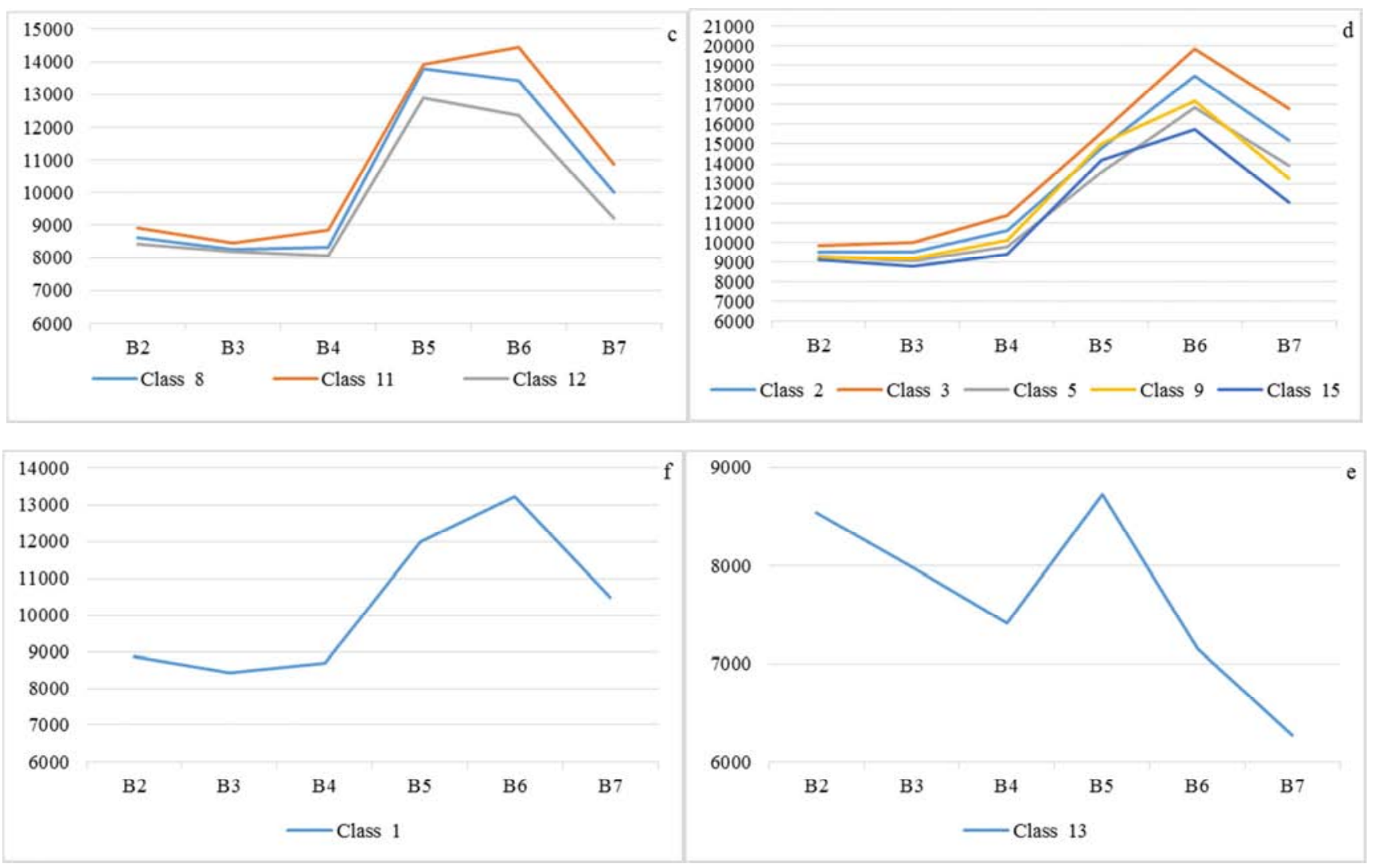

Figure 6. Spectral profiles of class groups.

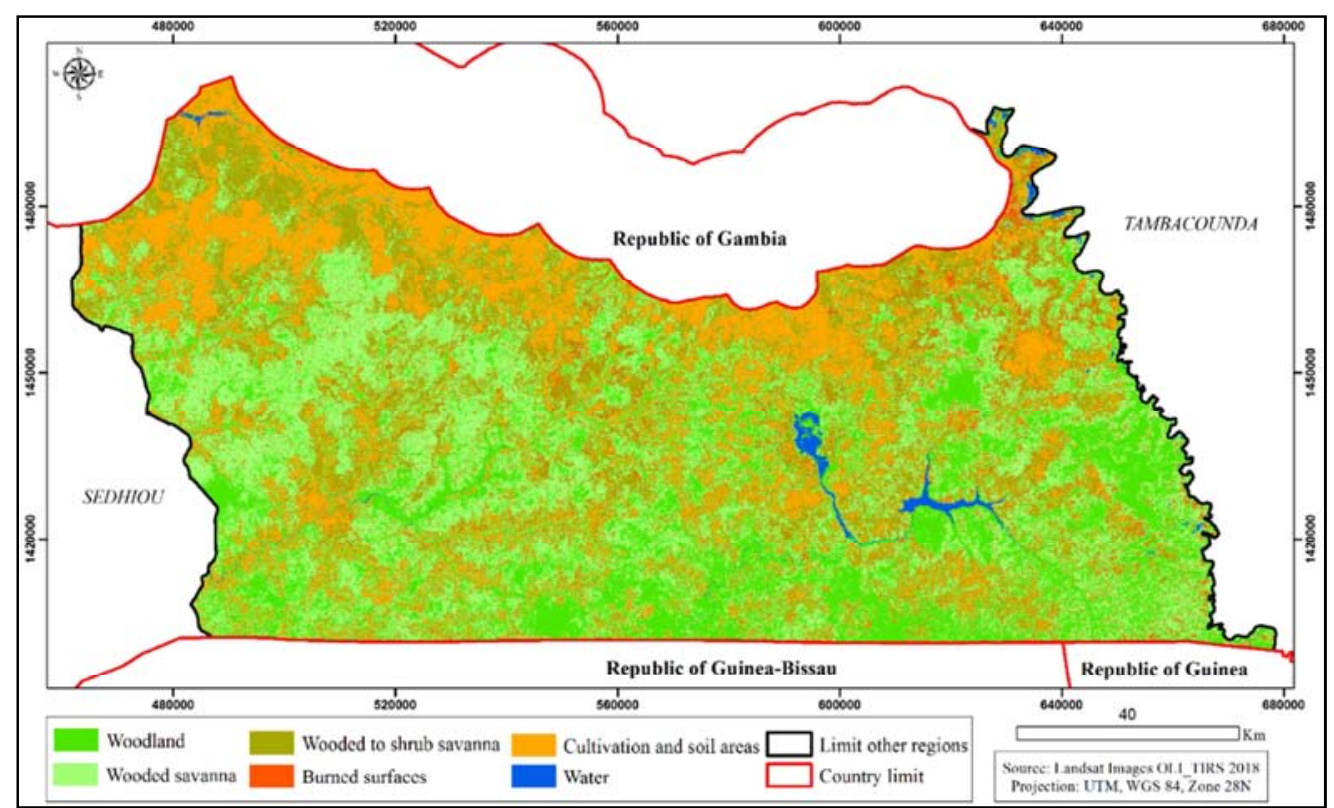

Figure 7. Grouping of unsupervised classification into thematic classes on 15 classes of the 2018 Landsat OLI_TIRS image.

Curves 7 and 14 have high absorption in red (B4) and in infrared (B7), and high reflectance in near infrared (B5), especially curve 14. Their fall from PIR to MIR is linear. They look like a healthy vegetation similar to a woodland. The main difference between these curves and those 4,6 , and 10 is the level of reflectance in the PIR, which happens to be lower. In addition, from PIR to MIR (B6), the latter are constant; with however a downward trend. They look like healthy vegetation this time, which is similar to the savanna, especially the wooded savanna.

Curves 8, 11, and 12 have a relatively low absorption in the red. In the PIR, their reflectance is strong; and very little more than those comparable to the wooded savanna. However, in the MIR (B6 and B7) their reflectance is even higher than that of other vegetation curves. This low absorption in the MIR (B7) is due to their low water content. 
Their appearance is that of the vegetation, but less healthy, similar to the wooded and shrub savanna.

Curves 2, 3, 5, 9, and 15 have a strong reflectance of green to infrared. They look like floors. These are areas of cultivation and soil. Curve 13 has a strong reflectance in the wavelengths of the visible, and a near-zero reflectance in the infrared, which suggests water. However, its reflectance in the PIR indicates the presence of plant pixels within it. Curve 1 has low reflectance in the green and red, and less reflectance in the PIR and MIR (B7). However, in the MIR (B6), its reflectance is relatively important. It clearly corresponds to the burns.

This interpretation of the curves allowed the different classes to be grouped with are similar spectral signatures and according to the chosen nomenclature (Figure 7). It should be noted that of the eight classes identified by visual interpretation, only two classes could not be separated from this first classification. These are the gallery forest and the plantations.

Thus, to move towards a precise and detailed mapping of land use, these classes have been corrected in several stages.

iii. checks and corrections

The verification and correction of classes required the development of thematic masks (Figure 8). Subsequently, we performed a classification in several steps on each mask.
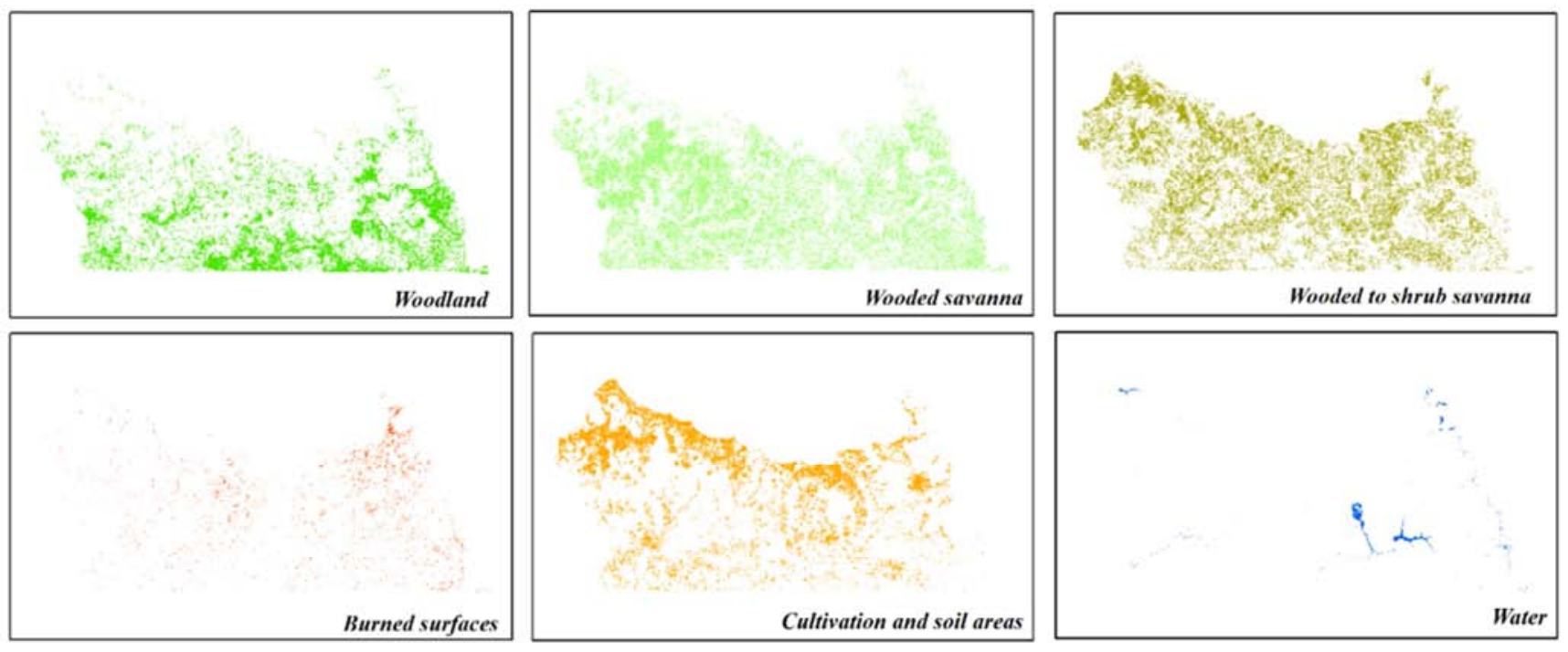

Figure 8. Mask of thematic classes from the collection of the Landsat OLI_TIRS 2018 image classification.

The goal is to check for groups of pixels that do not match the mask and then reassign them to the correct class. This operation took place as follows: classification on 10 classes using the mask, interpretation of the spectral signatures of the resulting classes, grouping of classes according to their similar signatures and the chosen nomenclature (Figures 9 to 14). The curves were interpreted according to the same criteria.

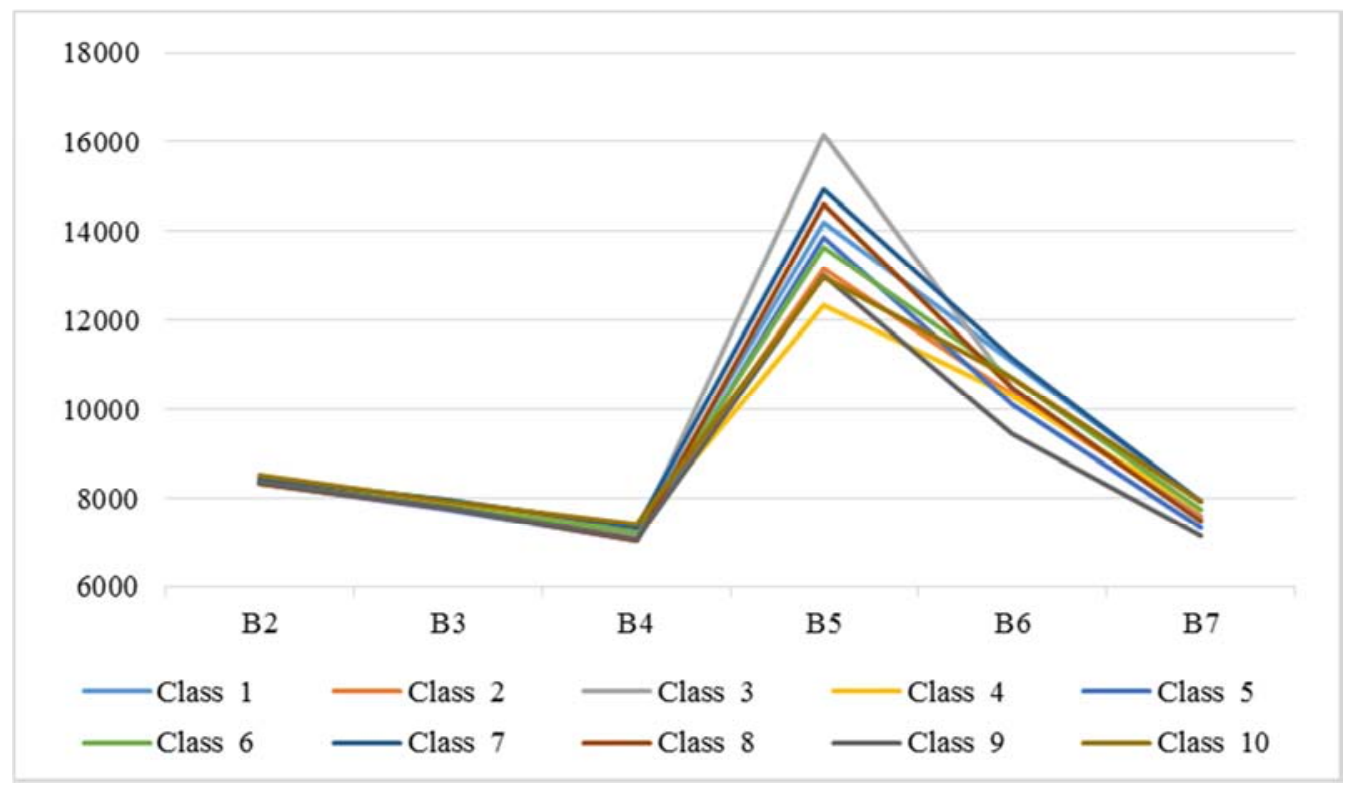

Figure 9. Histograms of the spectral signatures of the classification on the woodland mask. 
a. Checking the woodland mask

There are obviously four curves that differ from the others; and don't actually match the woodland class (Figure 9). These are curves 3, 4, 9 and 10. In the PIR, curve 3 has a very strong reflectance. Moreover, its fall is very significant in the MIR (B6). It resembles the curve of plantations formed mainly in the study area by orchards of "Anacardium occidentale L." and banana plantations. For curves 4 and 10, they increased slightly from the PIR before falling in the MIR (B6). Their peak in this part of the spectrum is outgoing. In addition, in the PIR, their reflectance is less important than that of the other curves. They are similar to the curves of the wooded savanna. Curve 9 is characterized by a high reflectance in the PIR with a value that does not reach that of curves similar to the woodland. Its reflectance in MIR is still very low due to its high water content. This is obviously the gallery forest. Checking the wooded savanna mask.

Three curves really stand out from the other curves of the classification on the wooded savanna mask (Figure 10). These are curves 4, 6 and 7. The main difference for curves 4 and 6 is the MIR (B6); where they are increasing before falling in the MIR (B7). In addition, for curve 4, a low reflectance is noted in the PIR. It is similar to the curve of burns. On the other hand, curve 6 is similar to the wooded to shrub savanna. As for curve 7 , its very strong reflectance in the PIR, and the pace of its fall from the MIR (B6) with an incoming peak, suggests plantations.

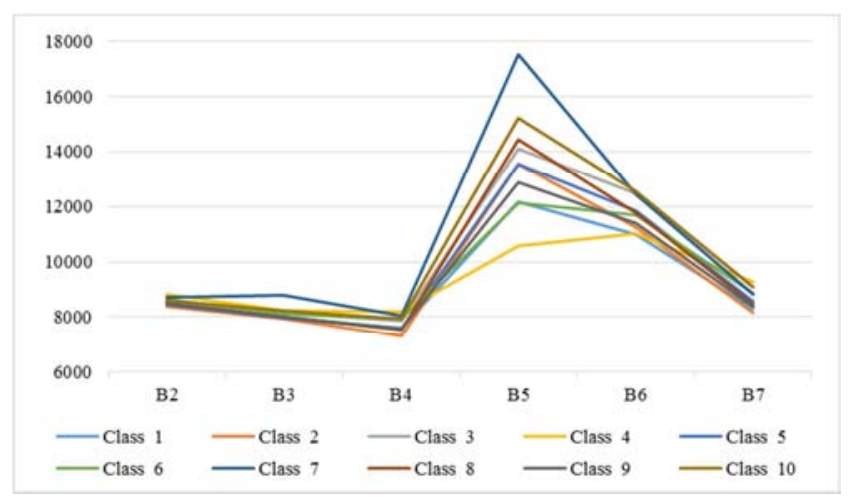

Figure 10. Histograms of the spectral signatures of the classification on the wooded savanna mask.

b. Checking the wooded to shrub savanna mask

There are three different profiles here (Figure 11). First, profile 9 has high absorption in the red, high reflectance in PIR, and lower reflectance in MIR. This curve is similar to that of the wooded savanna. Then there are curves 1 and 10 which are distinguished by a low absorption in the red and a higher reflectance in the MIR. This suggests the cultivations areas and soils.

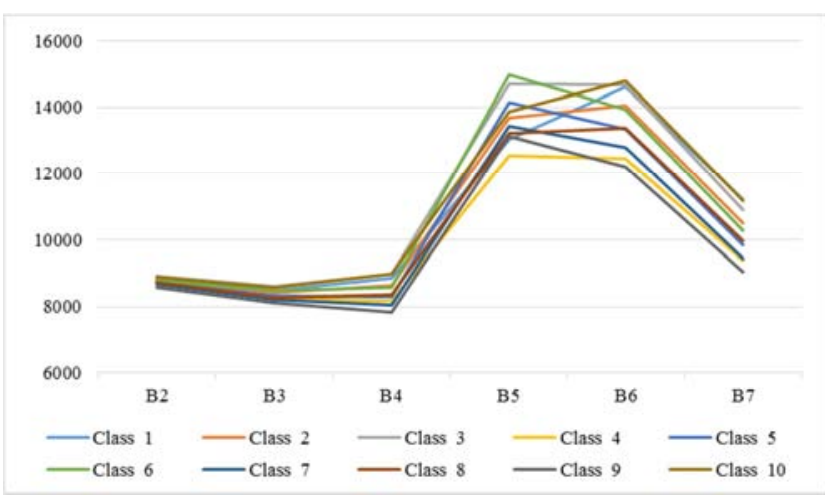

Figure 11. Histograms of the spectral signatures of the classification on the wooded to shrub savanna mask.

\section{c. Checking for burn mask}

Radiometric curves of the classification on the burn mask indicate that five curves have a different behavior (Figure 12). These are curves 1, 4 and 5 which look like cultivations areas and soils; and those 7 and 9 that look like the wooded to shrub savanna.

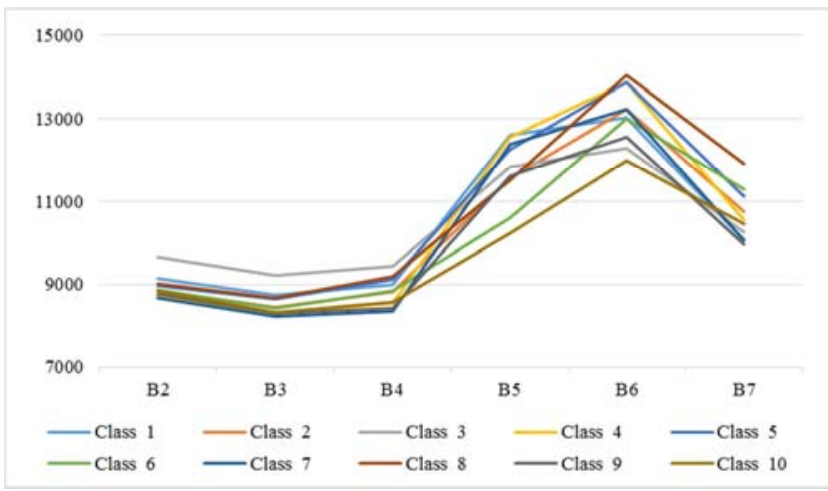

Figure 12. Histograms of the spectral signatures of the classification on the burn mask.

d. Checking the agricultural and soil surfaces mask

The classification on the mask of cultivations areas and soils indicates that all curves correspond to this class (Figure 13).

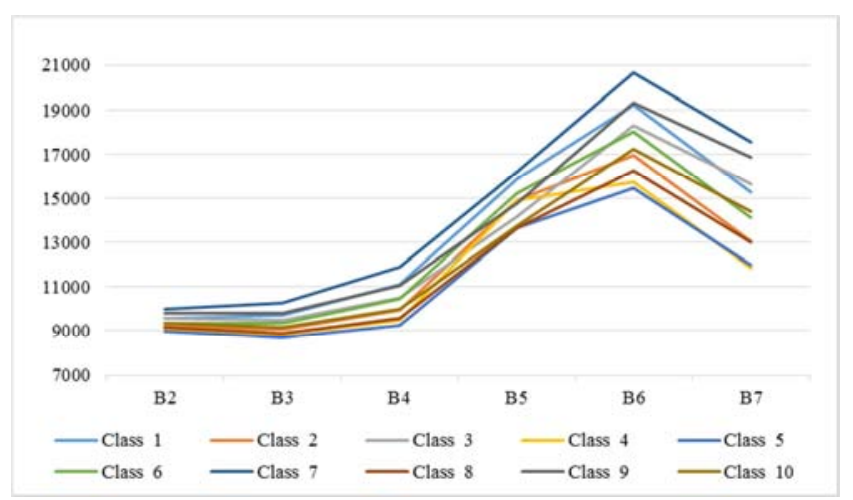

Figure 13. Histograms of the spectral signatures of the classification on the mask "cultivations areas and soils". 
e. Checking water mask

The classification on the water mask shows a clear difference between curves $1,3,5$ and 10 on the one hand; 2 , $4,6,7$, and 8 on the other hand, and curve 9 (Figure 14). The interpretation of these different paces being made upstream indicates that the first series corresponds to water; while the second is similar to the gallery forest. Curve 9 has the appearance of burns.

\subsubsection{Confronting Land Data, Ancient Works and Map Validation}

Validation of results is important in the mapping process. It ensures the performance of the results obtained and the significance of the analyzes succeeding them [31]. For this, we used the field truths for the most recent year (Figure 15) and by interpolation for the year 1987 .

We also used other sources of additional information. For the most recent year, this is the map of the large plant population areas produced at the scale of $1 / 50,000$ [51]. For the 1987 situation, we used the vegetation map of Senegal at $1 / 500,000$ [2]. We also used the 1/50,000 land cover changes cards from Senegal in 1975 and 2013 [7] and the Standard Vegetation Index (Figure 16) from the formula (PIR-R)/(PIR+R) [52].

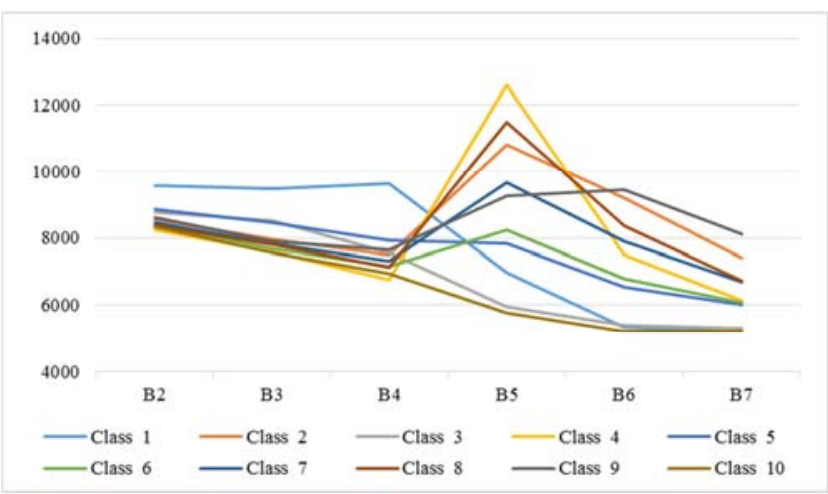

Figure 14. Histograms of the spectral signatures of the classification on the water mask.

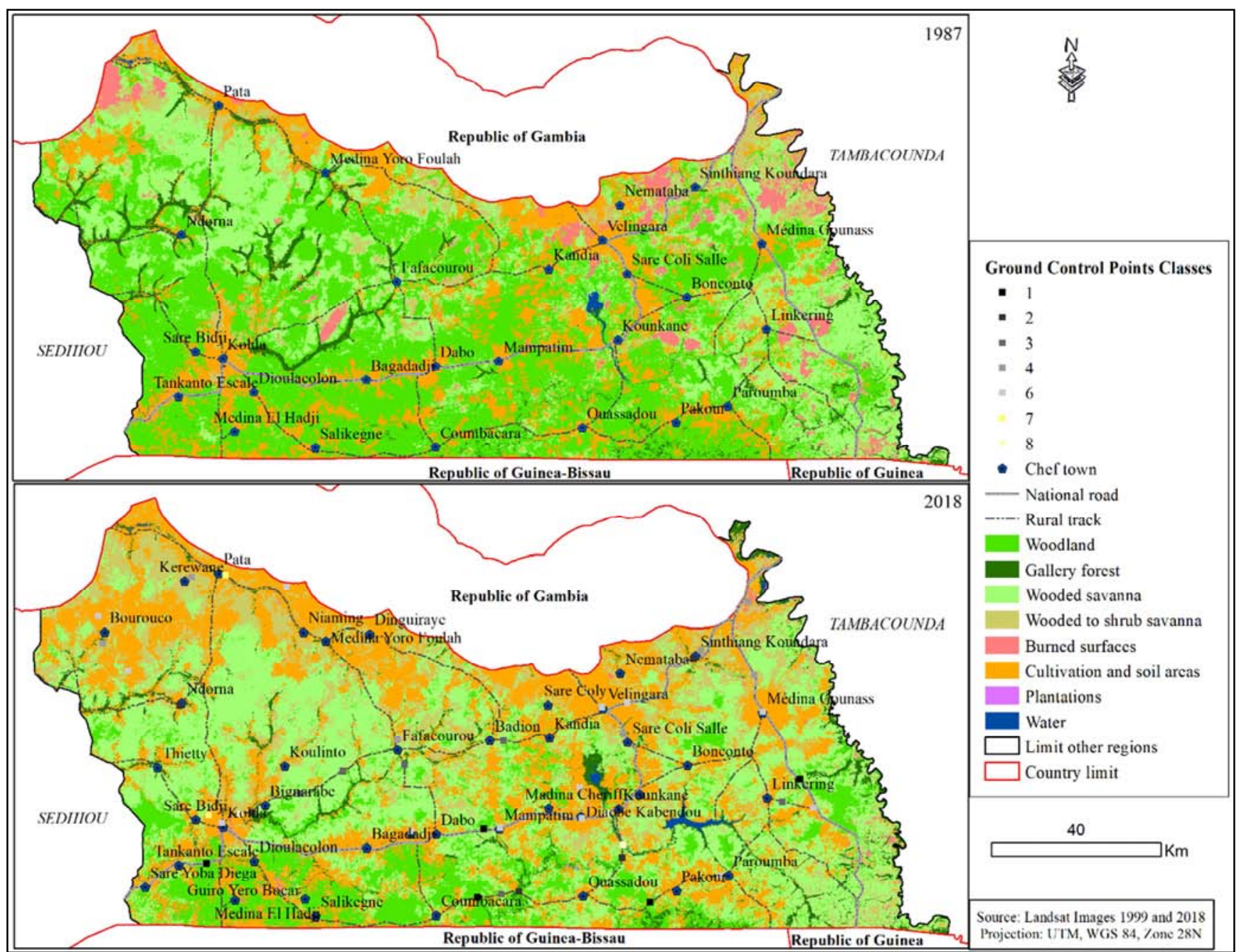

Figure 15. State of land use in 1987 and 2018. 


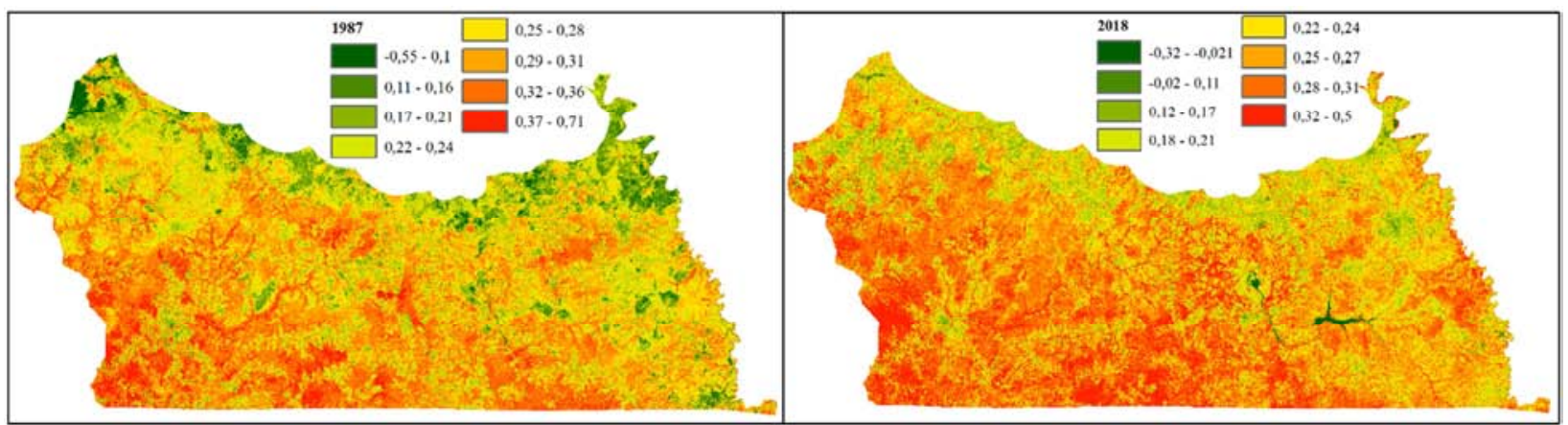

Figure 16. NDVI in 1987 and 2018.

\subsubsection{Mapping of Land Use Changes}

For the study of changes, we grouped the woodland and the gallery forest to form forest surfaces; and the wooded savanna plus the shrub tree to represent the wooded surfaces. Thereafter, classes were recoded from 1 to 6 . Then, we added the two images using the "Intersect" algorithm of the "Geoprocessing" extension of Arc GIS 10.5 software. The result of the addition and the statistical treatment show three changes: regressions, which correspond to the decrease of one class in favor of other (negative change); progression that corresponds to the increase of one class at the expense of other (positive change); stability, when a class does not change during the study period.

\section{Results}

\subsection{Spectral Profiles of Plant Formations in the Study Area}

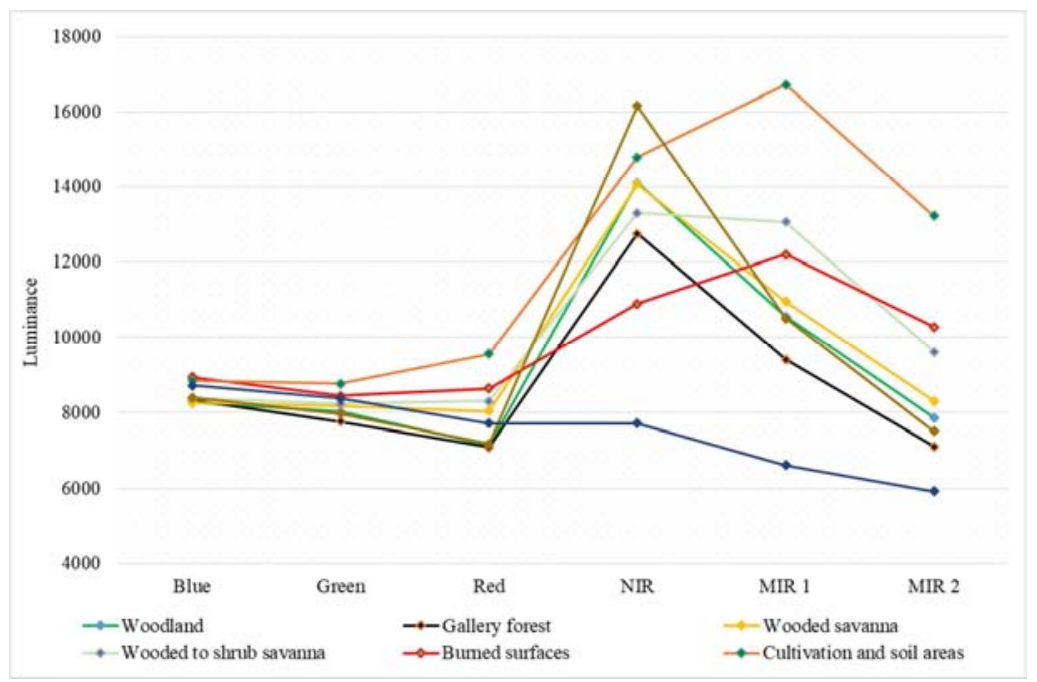

Figure 17. Spectral Profile of Land Use Classes in 2018.

Burned surfaces generally have low reflectance in the green, red, near infrared and far infrared (MIR 2). In the MIR 1, they have a strong reflectance. Crop areas and soils have a very strong reflectance in the visible and infrared. The plantations consisting mainly of anacard orchards and banana plantations in our study area have a low reflectance in the green and red. In PIR, they have a very strong reflectance. In the MIR 2, their
Multistage unsupervised classification allowed to contribute to the knowledge of the spectral profiles of land-use classes, particularly plant formations, in the different channels used (Figure 17).

In general, we can note that compared to savannas, forests are characterized by high absorption in the red, higher reflectance in near infrared, and lower reflectance in the medium infrared. In the near infrared, the denser the vegetation, the higher the reflectance values. Thus, the woodland is distinguished from the gallery forest by its peak which is more important in the PIR. However, in the MIR, its reflectance is higher than that of the gallery forest due to its high water content. As for the wooded savanna, it stands out from the wooded to shrub savanna because of its reflectance in the near infrared, which is more important. However, in the MIR 2, its reflectance is lower than that of the wooded to shrub savanna. reflectance is even lower than that of other vegetation classes except the gallery forest. Water is characterized by high reflectance in blue and low reflectance from green to infrared.

Of course, it should be noted that the luminance values vary according to the dates of shooting (year and month), the nature of the ground, its intensity, and its water content; hence, it is not possible to characterize afforestation by a standard 
spectral signature without taking into account the season [53].

\subsection{Changes in Land Use in 1987 and 2018}

The evolution of land use highlights an overall decrease in the woodland and an increase in the areas of savanna and cultivation and soil (Table 2). In 1987, forest areas occupied $607,844.4$ ha, or $44.1 \%$ of which $40.5 \%$ is occupied by woodland, and $3.6 \%$ by gallery forest. Savannas occupied
$433,509.7$ ha, or $31.5 \%$ of the land occupancy. They are dominated by the wooded savanna which occupies $339,747.7$ ha, or $245,985.7$ ha more than the wooded to shrub savanna. The surfaces that had been affected by the fires at that date capture covered $52,106.1$ ha, or $3.8 \%$. Cultivations areas and soils covered $280,490.4$ ha, or $20.4 \%$. Plants and water surfaces were 204.8 ha and $3,144.5$ ha, respectively.

Table 2. Area in hectares and percentage of land use in 1987 and 2018.

\begin{tabular}{|c|c|c|c|c|c|}
\hline \multirow{2}{*}{ Class } & \multicolumn{2}{|l|}{1987} & \multicolumn{2}{|l|}{2018} & \multirow{2}{*}{ Balance in ha } \\
\hline & $\mathrm{Ha}$ & $\%$ & Ha & $\%$ & \\
\hline Woodland & 557909,2 & 40,5 & 178272,1 & 12,9 & $-379637,1$ \\
\hline Gallery forest & 49935,2 & 3,6 & 52453,6 & 3,8 & 2518,4 \\
\hline Wooded savanna & 339747,7 & 24,7 & 498153,8 & 36,2 & 158406,1 \\
\hline Wooded to shrub savanna & 93762 & 6,8 & 198528,3 & 14,4 & 104766,8 \\
\hline Burned surfaces & 52106,1 & 3,8 & 6296,4 & 0,5 & $-45809,7$ \\
\hline Cultivation and soil areas & 280285,6 & 20,4 & 436361,1 & 31,7 & 156075,5 \\
\hline Water & 3144,6 & 0,2 & 4562,1 & 0,3 & 1417,5 \\
\hline Total & 1377095,2 & 100 & 1377095,2 & 100 & 0 \\
\hline
\end{tabular}

In 2018, the land occupancy is dominated by the wooded savanna and the cultivation and soil areas. Savannas increased by $263,172.9$ ha compared to 1987 ; and the growing and soil areas of $156,075.5 \mathrm{ha}$. The wooded savanna, with an area of $498,153.8$ ha or $36.2 \%$, increased by $158,406.1$ ha. The wooded to shrub savanna increased by $104,766.8$ ha.
Plantations and water surfaces have also increased. The increase in water surfaces was accompanied by the increase in the gallery forest of 2,518.4 ha. The woodland, with an area of $178,272.1$ ha or $12.9 \%$ of land cover, decreased by $379,637.1$ ha. The same is true of the surfaces affected by the burns.

\subsection{Changes in Cover Between 1987 and 2018}

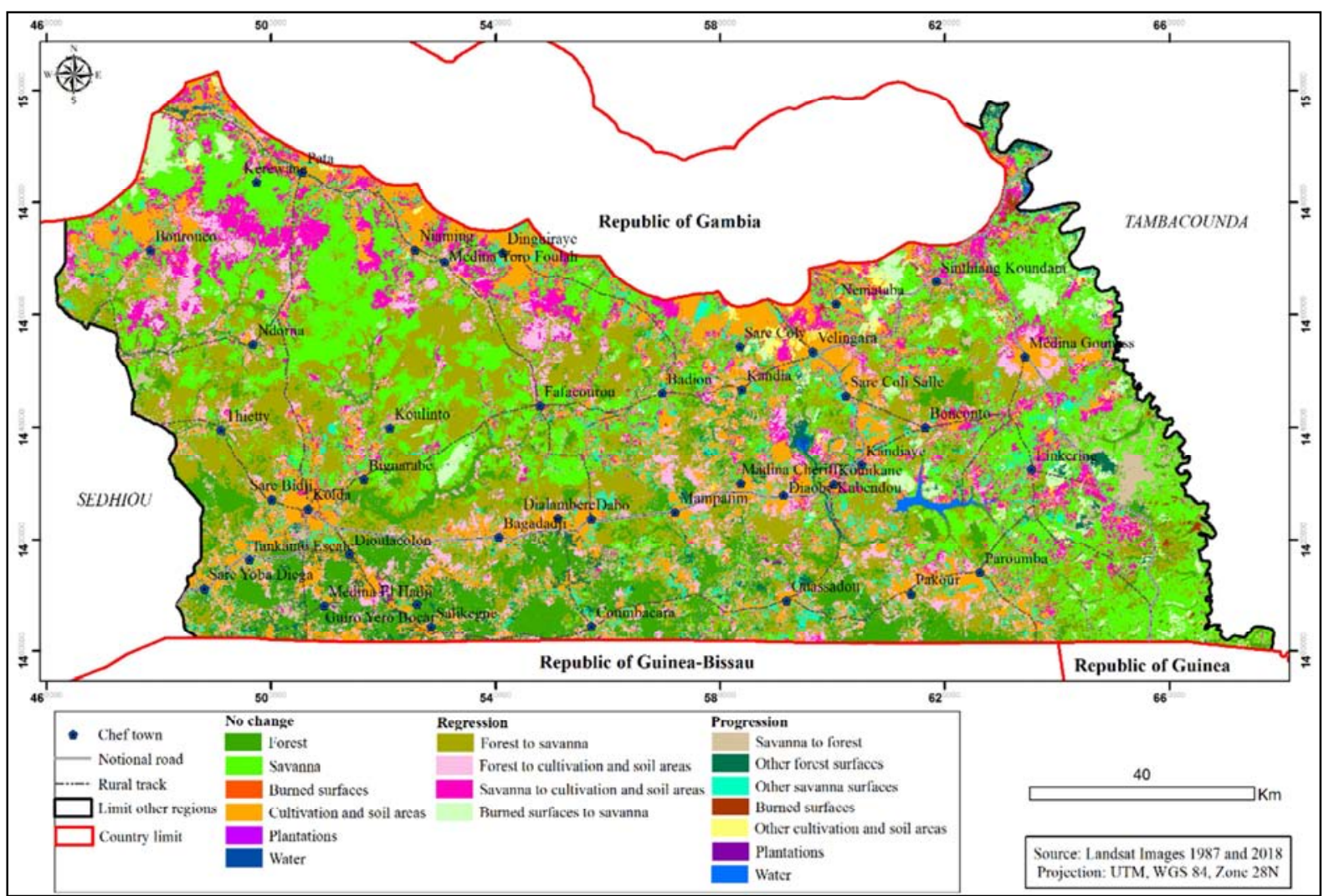

Figure 18. Changes in plant cover between 1987 and 2018. 
Mapping changes in vegetation cover indicates three major changes following a north-south gradient (Figure 18). Along the border with Gambia, large areas of forest and savanna have been transformed into agricultural and soil surfaces. The Pata listed forest is the most seriously affected by this change. This forest has been the subject of massive human occupation since the late 1970 s by agropastering migrants who have come to search for new agricultural land following the degradation of the land of the peanut basin and the lands of East Senegal to the point of having modified the original structure of the ecosystem. In the center-east, conversions of the vegetation cover were made around the Anambé watershed located near the listed forest of the same name.

In the center-west, we noticed a sharp decline in woodland surfaces in favor of the wooded savanna. It is the same in the southeast. In the southern part, we noticed three situations globally. This concerns the stability of forest surfaces, followed by an increase in savannas and agricultural and soil surfaces. However, reforestation was noted mainly in the east, in the Koulountou listed forest, and in the southwest.

The change matrices show that forest surfaces remained stable at $169,699.1 \mathrm{ha}$, or $12.3 \%$. The regression in favor of the savanna is $308,562.4$ ha (22.4 per cent); and $125,564.1$ ha, or $9.1 \%$ in favor of cultivation areas and soils (Table 3 ). In addition, a reforestation of $60,922.6$ ha, of which 34,109 ha was recorded on savanna surfaces.

The areas of savanna and cultivations areas and soils without change were $290,628.1$ ha $(21.1 \%)$ and 194,383 ha (14.1\%), respectively. A conversion of $104,185.3$ ha of savanna into agricultural areas and soils is noted. The areas affected by fire were predominantly savanna, i.e. 35,733.2 ha.

Table 3. Balance in hectare and percentage of changes in cover 1987-2018.

\begin{tabular}{llll}
\hline Changes & Class & Ha & \% \\
\hline \multirow{5}{*}{ No change } & Forest & 169699,1 & 12,3 \\
& Savanna & 290628,1 & 21,1 \\
& Burned surfaces & 820,3 & 0,1 \\
& Cultivation and soil areas & 194383 & 14,1 \\
& Plantations & 204,8 & 0,0 \\
& Water & 1076,8 & 0,1 \\
& Forest to savanna & 308562,4 & 22,4 \\
Regression & Forest to cultivation and soil areas & 125564,1 & 9,1 \\
& Savanna to cultivation and soil areas & 104185,3 & 7,6 \\
& Burned surfaces to savanna & 35733,2 & 2,6 \\
& Savanna to forest & 34109 & 2,5 \\
& Other forest surfaces & 26813,6 & 1,9 \\
& Other savannas surfaces & 61650,6 & 4,5 \\
Progression & Burned surfaces & 5472,1 & 0,4 \\
& Other cultivation and soil areas & 12125,6 & 0,9 \\
& Plantations & 2455,6 & 0,2 \\
& Water & 3611,7 & 0,3 \\
& & 1377095,2 & 100 \\
\hline
\end{tabular}

\section{Discussions}

The evolution of land use in Upper Casamance is marked by a sharp decline in the woodland in favor of savannas and cultivations areas and soils. Between 1987 and 2018, the woodland lost $379,637.1$ ha of its area, or $27.6 \%$; savannas that were both wooded and wooded to shrub increased by $158,406.1$ ha and 104,766.8 ha, respectively. Similarly, cultivations areas and soils increased by $156,075.5$ ha.

Thematically, this study is consistent with several work in Africa in general, and in Senegal in particular. Indeed, what is happening in Upper-Casamance is similar to what is happening in the Marahoué National Park in Côte d'Ivoire [22], in the Democratic Republic of Congo [21], in Gabon [54], in Gabon Benin's Sudano-Guinean zone [23], and in the Yangambi Biosphere Reserve [26]. In these areas, changes in vegetation cover and observed changes are mainly due to human pressure, both rural and urban, reflected in population growth and agricultural activities.

In Senegal, [2] and [5] noted that agricultural land is gaining ground on wooded savannas and woodlands in the center and south of the country. Similarly, [25] also mentioned a significant degradation of plant cover in Lower and Middle Casamance.

In our study area, the dynamics of agriculture are also at the heart of changes in vegetation cover and the anthropization of landscapes. It explains, through agricultural land clearing [10], the conversion of large forest and wooded areas along the border with Gambia and in the center of the study area. This situation arises as a result of the massive influx of agropastering migrants who have come in search of new farms and settled there [55]. They respond to the increase in the population, which in turn increases the demand for wood fuels and thus the abusive and illicit cutting of certain woody species for sale. In addition, wildfires are considered by many authors to be an important factor in the progression of savannas $[56,57]$ and degradation of vegetation [12]. They are one of the main causes of the relative slowness of forest growth in Senegal [58].

Methodologically, the use of multistage unsupervised classification proved to be effective. In their studies, $[25,33]$ have shown its effectiveness for a similar study applied to regions with similar physical characteristics to our. In contrast to their studies, our study sought also a better understanding of the spectral profiles of plant formation types encountered in the area and of radiometric values. These will allow, as noted [31], interpretation using similarity measurements when radiometric values of the class types present in the study area are available. The classification process will be directed from known spectral and temporal radiometric data obtained over different years or areas, rather than interpreting an unsupervised classification. According to him, this process is particularly suited to the treatment of large study areas offered by Landsat data.

\section{Conclusion}

Using the multistage unsupervised classification method, this study made it possible to map and quantify changes in land use and vegetation cover in Upper Casamance. On a thematic level, the results indicated that between 1987 and 2018 , forest areas decreased by $377,118.7$ ha (27.4\%), while wooded areas and cultivations areas and soil increased by $263,172.4$ ha $(19.1 \%)$ and $156,075.5$ ha $(11.3 \%)$ respectively. 
In terms of changes, three major changes are noted in a north-south gradient. These include deforestation by increasing agricultural and soil surfaces along the border with the Gambia, savanization and anthropization in along the central part, and stability of forest surfaces to savanization and anthropization in the south. However, reforestation has been noted in some places.

Methodologically, mapping being based on spatial and temporal variations in spectral signatures of land-use units, particularly of plants, has made it possible to contribute to the knowledge of spectral profiles of land-use classes, particularly of plant formations. It is important for future studies relating to areas with geographic and climatic characteristics similar to Upper Casamance.

\section{Acknowledgements}

The authors of this article would like to sincerely thank $\mathrm{Mr}$ Aruna M Jarju of King Graduate School-Monroe College (New York) for his corrections. The authors also thank him for the publication fees.

\section{References}

[1] Nouaceur, Z. Rain recovery and flooding in Sahel West Africa. Physio-Geo. 2020. 15, 89-109.

[2] Stancioff, A. Staljanssens, M. and Tappan, G. Mapping and remote sensing of the resources of the Republic of Senegal. Study of geology, hydrogeology, soils, vegetation and land use potentials. Remote Sensing Institute, SDSU-RSI-86-01, 1986. pp. 653 .

[3] Michel, P. The degradation of landscapes in Senegal. In "The degradation of landscapes in West Africa, J-F Richard. (eds)." Dakar Seminar, 21-26 November 1988. 1990. 37-53.

[4] Li, J. Lewis, J. Rowland, J. Tappan, G. and Tiezen, L. L. Evaluation of land performande in Senegal using multi-temporal NDVI and rainfall series. Journal of Arid Environments. 2004. 59, 463-480.

[5] Tappan, G. G. Sall, M. Wood, E. C. and Cushing, M. Ecoregions and land cover trends in Senegal. Journal of arid Environments. 2004. 59, 427-462.

[6] Hountondji, Y-C. H. Environmental dynamics in the Sahel and Sudanese areas of West Africa: Analysis of changes and assessment of degradation of the vegetal cover. Thesis of $\mathrm{PhD}$ in Science and Environmental Management at the University of Liège. 2008. pp. 181.

[7] CILSS. West African Landscapes: A Window on a Changing World. U.S. Geological Survey EROS, 47914 252nd St, Garretson, SD 57030, UNITED STATES, 2016. pp. 219.

[8] FAO. Global Forest Resources Assessment 2015. FRA data directory. Rome, Italy, 2015. pp. 244.

[9] Ariori, S. L. and Ozer, P. Development of forest resources in the Sahel West Africa over the last 50 years. Geo-Eco-Trop. 2005. 61-68.

[10] Solly, B. Dieye, E. H. B. Mballo, I. Sy, O. Sane, T. and Thior, M.
Spatio-temporal dynamics of forest landscapes in the south of Senegal: case of the department of Vélingara. Physio-Geo. 2020, 15, 41-67.

[11] Hamel, O. Dieng, C. Niang, A. Diop, A. B. Kairé, M. and Tamba, A. Covering Senegal's household energy needs by managed natural forests: dream or reality? Impacts on national policies and opportunities related to Carbon Mechanisms. Édit. PACAF-Sénégal/CASCADe-Afrique. 2011. pp. 26.

[12] Mbow, C. Spatio-temporal characteristics of wildfires and their relation to vegetation in Niokolo Koba National Park (southeastern Senegal). Thesis of PhD, 3rd Cycle of the Institute of Environmental Sciences, Dakar. 2000. pp. 120.

[13] Sane, T. Climate variability and its impact on the environment and human activities in Upper Casamance (South Senegal). PhD Thesis 3rd cycle of Geography, Cheikh Anta Diop University, Dakar. 2003. pp. 370.

[14] San Emeterio, J-L. Lacaze, B. and Mering, C. Detection of changes in vegetation cover in the Sahel during the period 1982-2002 from NDVI and rainfall data. Télédétection. 2011. $10(2-3), 135-143$.

[15] Herrmann, S. M. Anyamba, A. and Tucker, C. J. Recent trends in vegetation dynamics in the African Sahel and their relationship to climate. Global Approx. Change. 2005. 15, 394-404.

[16] Giffard, P. L. The tree in the Senegalese landscape. Forestry in dry tropical zone. Tropical Forestry Technical Center, Dakar, 1974. pp. 431.

[17] UNEP. The future of the environment in Africa, the past, the present and the future. Earthscan, United Kingdom, 2002. pp. 422 .

[18] Tsayem Demaze, M. Remote sensing as a tool to measure deforestation reduction (REDD). Remote Sensing Review, Research and Application, 2011.9 (3-4), 245-257.

[19] UNITED NATIONS. Rio Declaration on Environment and Development. Rio de Janeiro, 3-14 June 1992, A/CONF. 151/26, Vol. I, https://www.un.org/french/events/rio92/aconf15126vollf.htm.

[20] Chamard, P. C. and Courel, M. F. Sahelian forest threatened. Drought Paper, 1999. 10 (1), 11-18.

[21] Bamba, I. Anthropization and spatial-temporal dynamics of forest landscapes in the Democratic Republic of Congo. Thesis of $\mathrm{PhD}$ in Science, Université Libre de Bruxelles. 2010. pp. 189.

[22] Dibi N'Da, H. N'Guessan, E. K. Wajda, M. E. and Affian, $\mathrm{K}$. Remote sensing to monitoring deforestation in the Marahoué National Park (Côte d'Ivoire). Bulletin - French Society of Photogrammetry and Remote Sensing, 8 (1), 2008. 17-34.

[23] Mama, A. Bamba, I. Sinsin, B. Bogaert, J. and De Canniere, C. Deforestation, savanization and agricultural development of savanna-forest landscapes in the Sudano-Guinean area of Benin. Tropical wood and forests. 2014. 322 (4), 65-75.

[24] Sylla, D. Ba, T. and Guisse, A. Mapping of changes in vegetation cover in Ferlo protected areas (North Senegal): Biosphere Reserve case. Physio-Geo. 2019. 13, 115-132. 
[25] Diedhiou, I. Between the use and preservation of woody resources in West Africa: The dynamics of the forest landscapes in Southern Senegal. Thesis of Doctorate in Co-Trusteeship of the University of Paris and Assane Seck University of Ziguinchor, Senegal, 2019. pp. 444.

[26] Kyale Koy, J. Wardell, D. A. Mikwa, J.-F. Kabuanga, J. M. Monga Ngonga, A. M. Oszwald, J. and Doumenge, C. Dynamics of deforestation in the Yangambi Biosphere Reserve (Democratic Republic of Congo): Spatial and temporal variability over the past 30 years, Tropical Wood and Forests, 2019. 341, 15-28.

[27] Joly, G. Computer processing of satellite image. The EPI Bulletin. 1987. 47, 233-239.

[28] Girard, M. C. and Girard, C. M. Processing remote sensing data: Environment and natural resources. Dunod, Paris, 2nd edition, 2010. pp. 553.

[29] Caloz, R. and Collet, C. Remote Sensing Specifications. Geographic information system and digital image processing. University of Quebec Press/AUPELF-UREF, Sainte-Foy, 2001. 3, pp. 386.

[30] Idbraim, S. Methods for extracting spatial information and classifying in remote sensing imaging: Applications to thematic mapping of the Agadir region (Morocco). Thesis of $\mathrm{PhD}$ in Remote Sensing and Image Processing, University of Toulouse III - Paul Sabatier. 2009. pp. 143.

[31] Masse, A. Development and automation of classification methods from time series of remote sensing images Application to land use change and carbon balance estimation. $\mathrm{PhD}$ Thesis in Remote Sensing Image Processing, University of Toulouse III Paul Sabatier. 2013. pp. 223.

[32] Janodet, E. and Blasco, F. Green maps of vegetation and satellite remote sensing. Ed. AUPELF-UREF. Québec university press. 1993. 247-261.

[33] Andrieu, J. and Mering, C. Vegetation land cover change mapping of West African coastal zone from remotely sensed images: example of "Rivières-du-Sud" from Salum Delta (Senegal) to Rio Geba (Guinea-Bissau). Remote Sensing. 2008. 2. 93-118.

[34] Sagna, P. Climate dynamics and recent developments in the western part of West Africa. Thesis of Doctorate of State Es Lettres, Department of Geography, University Cheikh Anta Diop, Dakar. 2005. 1, pp. 270.

[35] Aubreville A. Yangambi Agreement on the nomenclature of African vegetation types. Bois et Forêts des Tropiques. 1957. 51. 23-27.

[36] Descoings, B. The herbal formations in the phytogeographical classification of Yangambi. Adansonia, ser. 2, 18 (2). Paris, 1978. 243-256.

[37] Da Lage, A. and Metailie, G. Dictionary of plant biogeography. CNRS Editions, Paris, 2005. pp. 579.

[38] Rodes Arnau, I. Estimate of large-scale land use for the exploitation of Earth observation images at high spatial, spectral and temporal resolutions. Thesis of $\mathrm{PhD}$ at the Center d'Études Spatiales de la BIOsphere, University Toulouse III Paul Sabatier, France. 2016. pp. 205.

[39] Ball, G. H. and Hall, D. J. ISODATA, a novel method of data analysis and pattern classification: DTIC Document. 1965.
[40] MacQueen, J. Some methods for classification and analysis of multivariate observations. Proceedings of the Fifth Berkeley Symposium on Mathematical Statistics and Probability. 1967. 1:281-297.

[41] Ducrot, D. Methods of analysis and interpretation of multi-source remote sensing images, extraction of landscape features. Research Brief, Entitlement to Conduct Research INP Toulouse, 2005. pp. 240.

[42] Guyot, G. and Saint, G. The main contributions of the international symposium "spectral signature of objects in remote sensing" in the spectral domain of the visible and near infrared. In "Proceedings of the International Symposium of the International Society for Photogrammetry and Remote Sensing", Vo12, Toulouse, 13-17 September, Ed.-Berlin, 1982. 95-108.

[43] Chaume, R. and Combeau, A. Comparative seasonal changes in spectral signatures of various perennial environments (forests, meadows, bare soils) from Landsat documents. Remote Sensing, ORSTOM, 1983. 8, pp. 49.

[44] Courel, M-F. Study of the recent evolution of the Sahel environment from satellite measurements. Thesis of Doctorate of State, Letters and Humanities, Université Panthéon-Sorbonne, Paris I, 1984. pp. 407.

[45] Guyot, G. Spectral Signatures of Natural Surfaces. Satellite Remote Sensing Collection, Paradigm, 1989. 43, 106145.

[46] Chamard, P. Courel, M-F. Ducousso, M. Guenegou, M-C. Le Rhun, J. Levasseur, J-E. Loisel, C. and Togola, M. Use of green and red spectral bands for better evaluation of active plant formations. Remote sensing and mapping. Ed. AUPELF-UREF. Les Presses de l’Université du Québec, 1993. 203-209.

[47] CSE Use of high-resolution satellite imagery. Technical Report, Edit, Ecological Monitoring Center, Dakar, Senegal, 1996. pp. 59.

[48] Chatelain, C. Pichiger, R. and Gautier, L. "Spectral signs and degradation of the dense wet forest cover of Côte d'Ivoire". In: Remote Sensing in La Francophonie: critical analysis and perspectives. Ed. AUF. 2000. 349-355.

[49] Boulogne, M. Vulnerability of forest landscapes in Ranomafana Park (Madagascar): environmental dynamics and agroforestry trajectories. Thesis of PhD, Université Grenoble Alpes. 2016. pp. 269.

[50] Dessay, N. The dynamics of vegetation and climate: remote sensing study of five Brazilian biomes, dense and open rainforest, Cerrados, Caatinga and Campanha Gaúcha. PhD thesis, Université Paris X Nanterre, 2006. pp. 364.

[51] ANAT. National Plan for Spatial Development and Development (NAPDP) 2035. Provisional version, Edition, National Agency for Land Management. Dakar. Senegal, 2018. p. 277.

[52] Rouse, J. W. Haas, R. W. Schell, J. A. Deering, D. W. and Harlem, J. C. Monitoring the vernal advancement and retrogradation (Greenwave effect) of natural vegetation. NASA/GSFC Type-III, Final Report, Greenbelt, Maryland. 1974. pp. 164.

[53] Muller, E. "Test for a standard spectral signature database: application in the Garonne Valley (France)". In: Remote Sensing in La Francophonie: critical analysis and perspectives. Ed. AUF. 2000. 349-355. 
[54] Desclees, B. Mayaux, P. Hansen, M. Lola Amani, P. Sannier, C. Mertens, B. Häusler, T. Ngamabou Siwe, R. Poilve, H. Gond, V. Rahm, M. Haarpaintner, J. and Kibambe Lubamba, J. P. "Evolution of forest cover from national to regional level and drivers of change". In: De Wasseige C. (ed.), Flynn J. (ed.), Louppe D. (ed.), Hiol Hiol F. (ed.), Mayaux P. (ed.) The forests of the Congo Basin: state of the forests 2013. Neufchâteau: Weyrich, 2014. 21-46.

[55] Fanchette, S. A peripheral region in the test of decentralization: Fuladu, the Peul country of Upper-Casamance (Senegal). Paris, Karthala, (Men and Companies). IRD. 2011.pp. 393.
[56] Aubreville, A. Climates, forests and desertification of tropical Africa. Geographic, maritime and colonial publishing company, Paris. 1949. pp. 351

[57] Jacquin, A. Vegetation dynamics of savannas in relation to the use of fires in Madagascar. Time series analysis of remote sensing images. $\mathrm{PhD}$ thesis in Functioning of ecosystems and agrosystems, University of Toulouse. 2010. pp. 144.

[58] Chave, J. The spatial-temporal dynamics of the rainforest. Ann. Phys. Fr. 25, 2000. 6, p. 184. 